\title{
Analisis Lembar Kerja Peserta Didik (LKPD) Berbasis Problem Based Learning Terhadap Hasil Belajar Siswa
}

\section{Citra Gusyanti ${ }^{1}$, Sujarwo ${ }^{2}$}

1,2 Universitas Muslim Nusantara Al-Washliyah

\section{Corresponding Author : citranasution6@gmail.com}

\section{ABSTRACT}

Researchers have a goal to describe how the analysis of student worksheets (LKPD) based on problem based learning (PBL) on student learning outcomes. The results of the research are that (1.) The use of LKPD based on Problem Based Learning as teaching materials has a positive effect of $80 \%$ in improving student learning outcomes. (2.) Problem Based Learning-based worksheets are appropriate to be used as learning materials in schools, because the use of Problem Based Learning-based worksheets in the teaching and learning process can help students understand learning so that the success of the teaching and learning process will be achieved. (3.) The advantages of LKPD based on Problem Based Learning as teaching materials can be said to be superior in that application, learning becomes more effective and efficient, making the learning process more interesting and can improve the quality of learning well.

Kata Kunci

LKPD, Problem Based Learning, Hasil Belajar

\section{PENDAHULUAN}

Hakikat pendidikan merupakan suatu usaha bersama antara pemerintah dengan masyarakat yang dilakukan secara sadar, berencana, sistematis, dan berkesinambungan. Bertujuan mempersiapkan dan mengembangkan kepribadian dan tingkah laku yang baik yang sesuai dengan pancasila, serta pengetahuan siswa yang akan dapat dipergunakan kelak untuk ikut berpartisipasi dalam perkembangan nasional. Hal tersebut selaras jika ditinjau dari sudut hukum, definisi pendidikan berdasarkan Undang-Undang RI No. 20 Tahun 2003 tentang sistem pendidikan nasional, yaitu pendidikan adalah usaha sadar dan terencana untuk mewujudkan suasana belajar dan proses pembelajaran agar peserta didik secara aktif mengembangkan potensi dirinya untuk memiliki kekuatan spiritual keagamaan, pengendalian diri, kepribadian, kecerdasan, akhlak mulia, serta keterampilan yang diperlukan dirinya, masyarakat, bangsa, dan negara.

Salah satu cara untuk membentuk sumber daya manusia yang baik adalah dengan meningkatkan mutu pendidikan. Melalui kegiatan proses pembelajaran yang efektif dan efisien akan tercipta mutu pendidikan yang baik. Dari proses pembelajaran yang baik maka akan mendapatkan hasil belajar peserta didik dengan baik. Banyak yang dapat mempengaruhi hasil belajar siswa seperti 
Cybernetics: Journal of Research and Educational Studies

Volume 2 Nomor 4, Oktober 2021

Halaman 123-130

bahan ajar dan model pembelajaran yang digunakan oleh guru untuk membantu mengingkatkan hasil belajar serta membantu mencapai tujuan pembelajaran.

Kenyatan yang terjadi dilapangan melalui observasi awal yang dilakukan peneliti yang mengamati Proses Belajar Mengajar (KBM) disekolah terdapat beberapa permasalahan diantaranya kurangnya penggunaan bahan ajar yang tepat. Bahan ajar yang digunakan hanya buku paket dan LKPD yang digunakan sebagai alat evaluasi setelah pembelajaran. Tak jarang guru menjadi sumber belajar pertama dan utama dalam pembelajaran, sehingga hal tersebut mengakibatkan siswa hanya mencapai tingkat penanaman konsep (mengingat dan memahami) dan belum sampai tingkat seperti mengaplikasikan, menganalisis, mengevaluasi, dan menyajikan. Dari pembelajaran yang seperti ini didapatlah siswa yang pasif dan hasil belajar siswa yan rendah. Hal tersebut tampak dari tingkah laku siswa saat mengikuti proses pembelajaran. Siswa menjadi pasif dan tidak menunjukkan respon yang aktif terhadap penjelasan yang dijelaskan oleh guru, malas bertanya, dan tidak fokus terhadap penjelasan dari guru. Beberapa diantaranya bahkan tidak memperhatikan dan mengacuhkan penjelasan dari guru.

Sebagian besar sekolah menggunakan LKPD sebagai bahan evaluasi dan tidak difungsikan sebagaimana fungsinya. Pada umumnya LKPD hanya berisi materi singkat dan soal individu. Sehingga terkadang peserta didik mengalami kesulitan dalam menyelesaikan soal dikarenakan tidak paham terkait pembelajaran serta materi yang disajikan hanya terlalu singkat yang dapat menyebabkan rendahnya hasil belajar siswa.

Meninjau permasalahan tersebut maka sudah selayaknya guru menggunakan bahan ajar dan model pembelajaran yang inovatif sehingga dapat membantu proses pembelajaran sampai mencapai tujuan pembelajaran yang dapat meningkatkan hasil belajar siswa. Sehingga dibutuhkannya LKPD yang efektif dan efisien sebagai bahan ajar untuk dapat membantu peroses belajar mengajar mencapai tujuan. LKPD dapat dipadukan dengan model pembelajaran agar dapat menjadi bahan ajar yang efektif dan efisien serta dapat meningkatkan hasil belajar siswa. Salah satu model pembelajaran yang dapat digunakan adalah problem based learning .

Dari pengertian diatas dapat dikatakan LKPD berbasis adalah salah satu model LKPD yang berpusat pada meningkatkan efektifitas pembelajaran. Pengembangan LKPD berbasis problem based learning pada siswa sebagai pendamping bagi kegiatan belajar siswa diharapkan mampu meningkatkan kualitas pembelajaran, sehingga hasil belajar siswa dapat meningkat. 
Cybernetics: Journal of Research and Educational Studies

Volume 2 Nomor 4, Oktober 2021

Halaman 123-130

Berdasarkan uraian latar belakang diatas, penulis. tertarik untuk melaksanakan penelitian dengan judul: "Analisis Lembar Kerja Peserta Didik (LKPD) Berbasis Problem Based Learning Terhadap Hasil Belajar Siswa".

\section{METODE PENELITIAN}

Penelitian yang dilakukan peneliti di perpustakan Universitas Muslim Nusantara Al-Washliyah selama 7 hari memperoleh hasil penelitian berupa data kualitatif. Desain penelitian ini menggunakan pendekatan penelitian yang digunakan adalah pendekatan kualitatif. Menurut Sugiyono (2019:18) "Penelitian kualitatif adalah metode penelitian yang berlandaskan filsafat post positivisme, digunakan untuk meneliti pada kondisi obyek yang alamiah, (sebagai lawannya eksperimen) dimana peneliti adalah sebagai instrument kunci, teknik pengumpulan data dilakukan secara trianggulasi (gabungan), analisis data bersifat induktif/kualittaif, dan hasil penelitian lebih menekankan makna dari pada generalisasi.

Jenis penelitian yang termasuk dalam penelitian dengan pendekatan kualitatif diataranya studi kasus, biografi, etnografi, dan library search. Dalam penelitian ini jenis penelitian yang peneliti lakukan masuk kedalam penelitian literatur atau kepustakaan (library search).

\section{HASIL PENELITIAN DAN PEMBAHASAN Deskripsi Hasil Penelitian}

Bahan ajar merupakan salah satu bagian dalam proses pembelajaran. Bahan adalah seperangkat sarana atau alat pembelajaran, metode, batasan-batasan, dan cara mengevaluasi yang didesain secara sistematis dan menarik dalam rangka mencapai tujuan yang diharapkan yaitu mencapai kompetensi dan subkompetensi dengan segala kompleksitasnya. LKPD merupakan suatu bahan ajar cetak berupa lembar-lembar kertas yang berisi materi, ringkasan, dan petunjuk-petunjuk pelaksanaan tugas pembelajaran yang harus dikerjakan oleh peserta didik, yang mengacu pada kompetensi dasar yang harus dicapai. Bahan ajar LKPD ini akan berjalan yang efektif jika dibantu dengan model pembelajaran Problem Based Learning merupakan sebuah model yang membuat pembelajaran menjadi lebih aktif dan bermakna serta melibatkan siswa secara langsung. Dengan adanya model pembelajaran problem based learning ini kegiatan belajar mengajar dapat berjalan dengan efektif, dimana model pembelajaran ini menutut siswa untuk aktif dalam memcahkan masalah dalam pembelajaran. Kelebihan diri penggunaan LKPD berbasis problem based learning akan meningkatkan kualitas belajar siswa dikelas. Penggunaan LKPD berbasis problem based learning dalam proses belajar mengajar dapat menambah pemahamn siswa serta 
Cybernetics: Journal of Research and Educational Studies

Volume 2 Nomor 4, Oktober 2021

Halaman 123-130

membuat siswa lebih aktif. Dengan adanya penggunaan LKPD berbasis problem based learning ini mampu meningkatkan hasil belajar siswa.

Dalam penelitian ini peneltit menganalisi 10 jurnal relevan tentang LKPD berbasis problem based learning. Analisis jurnal yang dilakukan oleh peneliti dilakukan untuk mengetahui bagaimana analisis penggunaan LKPD berbasis problem based learning dalam menungkatkan hasil belajar siswa. Dengan menetapkan fokus masalah penelitian yang berdasarkan observasi saat peneliti melakukan observasi jurnal secara langsung yaitu mengobsevasi di perpustakaan Universias Muslim Nusantara Al-Washliyah. Dari observasi yang sudah peneliti lakukan menunjukkan bahwa adanya model pembelajaran yang masih monoton dan adanya penggunaan bahan ajar yang masih konvensional, sehingga diperlukan adanya perubahan untuk dapat meningkatkan hasil belajar siswa. Model pembelajaran yang diterapkan guru saat pebelajaran berlangsung masih menggunakan metode ceramah yang membuat siswa mudah merasa bosan. Sehingga siswa tidak memperlihatkan guru dalam menerangkan pembelajaran. Dan bahan ajar yang digunakan disekolah tersebut juga masih menggunakan bahan ajar konvensional, seperti buku paket, dan Lembar Kerja Siswa (LKS) padahal terdapat banyak bahan ajar yang dapat digunakan atau dikembangkan guna membuat kegiatan pembelajaran menjadi lebih aktif dan menarik sehingga dapat meningkatkan hasil belajar siswa. Jadi dapat disimpulkan bahwa guru sebaiknya menggunakan Lembar Kerja Peserta Didik (LKPD) berbasis problem based learning agar dapat meningkatkan hasil belajar siswa.

Peneliti juga sudah menganalisis 10 jurnal yang berhubungan tentang Lembar Kerja Peserta Didik (LKPD) berbasis problem based learning. Salah satu penelitian yang sudah dilakukan ialah oleh Wahyu Rizki dkk, yang mengatakan bahwa terdapat pengaruh Lembar Kerja Peserta Didik (LKPD) berbasis problem based learning terhadap peningkatan hasil belajar dengan menunjukkan hasil belajar siswa 7,137 > 2,002 dengan uji t yang artinya pemanfaatan LKPD berbasis PBL dapat meningkatkan hasil belajar siswa. Sedangkan menurut penelitian yang telah dilakukan oleh peneliti Oktavia Dwi Lestari dkk, menyatakan bahwa hasil analisis keterlaksanaan tersebut dapat dikatakan LKPD berbasis Problem Based Learning layak digunakan dalam pembelajaran karena ketiga pertemuan menggunakan LKPD memperoleh rata-rata keterlaksanaan kegiatan lebih dari $75 \%$. 
Cybernetics: Journal of Research and Educational Studies

Volume 2 Nomor 4, Oktober 2021

Halaman 123-130

\section{Pembahasan Hasil Penelitian}

\section{Pengaruh Lembar Kerja Peserta Didik (LKPD) Berbasis Problem Based Learning}

Hasil penelitian mentakan bahwa LKPD berbasis problem based learning sebagai bahan ajar dalam meningkatkan hasil belajar siswa dan sangat berpengaruh positif hal ini terlihat pada penelitian-penelitian terdahulu. Bahan ajar mempunyai peran yang sangat penting dalam proses belajar mengajar. Dengan penggunaan bahan ajar, diharapkan dapat membantu siswa dalam memahami pembelajaran sehingga keberhasilan proses belajar mengajar akan tercapai. Hal ini sejalan dengan pendapat Letna Sugiarti dalam Fashion and Fashion Education Journal (2013:49) yaitu bahan ajar merupakan seperangkat materi yang disusun secara sistematis baik tertulis maupun tidak, sehingga tercipta suatu lingkungan/suasana yang memungkin siswa untuk belajar. Bahan ajar yang menjadi pedoman siswa dalam proses belajar turut menjadi bagian dalam mencapai tujuan pembelajaran tersebut. Bahan ajar yang bermutu dan berkualitas baik serta tepat dan sesuai akan mempermudah dalam mencapai tujuan pembelajaran.

Maka dari itu penggunaan LKPD berbasis problem based learning sangat layak digunakan dalam proses belajar mengajar. Bahan ajar dan model pembelajaran ini juga sudah diuji adanya pengaruh oleh peneliti sebelumnya dan mendapatkan hasil yang layak untuk digunakan dalam proses belajar mengajar. Berdasarkan hasil analisis tentang penggunaan LKPD berbasis problem based learning maka peneliti dapat menyimpulkan bahwa terdapat pengaruh ialah:

a. LKPD berbasis problem based learning sangat menarik untuk digunakan dalam proses belajar mengajar sehingga mampu meningkatkan hasil belajar siswa

b. LKPD berbasis problem based learning sangat memudahkan siswa dalam memecahkan masalah dalam pembelajaran.

c. LKPD berbasis problem based learning membantu guru menyampaikan materi dan evaluasi siswa.

d. LKPD berbasis problem based learning membantu siswa dalam berkomunikasi dan evaluasi siswa. 
Cybernetics: Journal of Research and Educational Studies

Volume 2 Nomor 4, Oktober 2021

Halaman 123-130

\section{KESIMPULAN}

Berdasarkan serangkaian penelitian yang telah dilakukan dapat disimpulkan bahwa beberapa hal diantaranya sebagai berikut:

1. Pemanfaatan LKPD berbasis Problem Based Learning sebagai bahan ajar berpengaruh positif sebesar $80 \%$ dalam meningkatkan hasil belajar siswa

2. LKPD berbasis Problem Based Learning layak digunakan sebagai bahan bajar disekolah, karena penggunaan LKPD berbasis Problem Based Learning dalam proses belajar mengajar dapat membantu siswa dalam memahami pembelajaran sehingga keberhasilan proses belajar mengajar akan tercapai.

3. Keunggulan LKPD berbasis Problem Based Learning sebagai bahan ajar dapat dikatakan unggul didalam aplikasi tersebut pembelajaran menjadi lebih efektif dan efisien membuat proses pembelajaran menjadi lebih menarik serta dapat meningkatkan kualitas belajar dengan baik.

\section{REFERENCE}

Aini, NA.dkk. (2017). Pengembangan LKPD Berbasis Problem Based Learning Pada Mata Pelajaran IPA Materi Gaya. (Juni 2020).

Amir, Z.dkk. (2019). Pengembangan Lembar Kerja Peserta Didik (LKPD) Matematis Berbasis PBL Terintegrasi Nilai-Nilai Islam Di Sekolah Dasar Islam Terpadu.

Arikunto, Suharsimi. 2017. "Prosedur Penelitian: Suatu Pendekatan Praktik". Jakarta: Rineka Cipta.

Arsanti, M. (2018). Pengembangan Bahan Ajar Mata Kuliah Penulisan Kreatif

Bermuatan Nilai-Nilai Pendidikan Karakter Religious Bagi Mahasiswa

Prodi PBSI FKIP, UNISSULA. (Februari 2020).

Asriningtyas, AN,dkk. (2018). Penerapan Model Pembelajaran Problem Based Learning Untuk Meneingkatkan Kemampuan Berpikir Kritis dan Hasil Belajar Matematika Siswa Di Kelas IV SD.

Fauzia, HA. (2018). Penerapan Model Pembelajaran Problem Based Learning Untuk Meningkatkan Hasil Belajar Matematika SD.

Gunantara, GD,dkk. (2014). Penerapan Model Pembelajaran Problem Based Learning Untuk Mneingkatkan Kemampuan Pemecahan Masalah Matematika Siswa Kelas V. Prodi PGSD FKIP, Universitas Pendidikan Ganesha.

Gultom, T. (2020). Penilaian Kinerja Guru Mengenai Profesionalisme Guru Di Smp Negeri 2 Pangaribuan Kabupaten Tapanuli Utara Tahun 2020. Journal Of Education And Teaching Learning (JETL), 2(3), 29-43. https://doi.org/10.51178/jetl.v2i3.66

Ismail, Nurdin. Sri Hartati.2019. Metodologi Penelitian Sosial. Surabaya: Media Sahabat Cendikia. 
Cybernetics: Journal of Research and Educational Studies

Volume 2 Nomor 4, Oktober 2021

Halaman 123-130

Johannes, J. (2021). Meningkatkan Hasil Belajar Siswa Menggunakan Model Pembelajaran Make A Match Pada Pelajaran IPA Materi Sifat-Sifat Cahaya Di Kelas V SD Negeri 060952 Medan Labuhan T.P. 2019/2020. Journal Of Education And Teaching Learning (JETL), 3(1), 50-61. https:// doi.org/10.51178/jetl.v3i1.123

Kristyowati, R, (2018). Lembar Kerja Peserta Didik (LKPD) IPA Sekolah Dasar Berorientasi Lingkungan.

Kusumam, A. (2016). Pengembangan Bahan Ajar Mata Pelajaran Dasar dan Pengukuran Listrik Untuk Sekolah Menengah Kejuruan. (Maret 2020).

Lumbangaol, T. (2020). Penerapan Strategi Pembelajaran Mind Mapping Untuk Meningkatkan Hasil Belajar Siswa Pada Materi "Teks Panjang" Mata Pelajaran Bahasa Indonesia di SDN 173346 Dolok Martumbur Kecamatan Muara Kelas IV T.P 2018/2019. Journal Of Education And Teaching Learning (JETL), 2(2), 27-34. https:/ / doi.org/10.51178/jetl.v2i2.62

Mendiknas, (2008). Peraturan Menteri Pendidikan Nasional Nomor 2 Tahun 2008 tentang Buku.

Mudlofir, A,dkk. (2016). Desain Pembelajaran Inovatif. Jakarta:Charisma Putra Utama Offset.

Muamar Al Qadri, S. W. (2021). Pengaruh Home Visit Method Terhadap Hasil Belajar Luring di Masa Pandemi COVID-19 Pada Mata Pelajaran Al Qur'an Hadits (Studi Kasus Siswa Kelas VIII MTS Jam'iyah Mahmudiyah Tanjung Pura Langkat). Continuous Education: Journal of Science and Research, 2(1), 6171. https:// doi.org/10.51178/ce.v2i1.187

Purwanto. (2011). Evaluasi Hasil Belajar, Yogyakarta: Pustaka Belajar

Rani, AR.dkk. (2019). Pengembangan Lembaran Kerja Peserta Didik Dengan Model Problem Based Learning Pada Siswa Kelas IV Sekolah Dasar. (Juni 2020).

Rizki, W. (2016). Pemanfaatan Lembar Kerja Peserta Didik (LKPD) Berbasis Problem Based Learning (PBL) Terhadap Peningkatan Hasil Belajar Siswa Di Rukoh Kota Banda Aceh. (Mei 2020)

Sudjana, Nana. (2019). Penilaian Hasil Belajar Mengajar. Bandung: Remaja Rosdakarya.

Sulastri, Imran,dkk.(2013).Meningkatkan Hasil Belajar Siswa Melalui Strategi Pembelajaran Berbasis Masalah Pada Mata Pelajaran IPS di Kelas V SDN 2 Limbo Makmur Kecamatan Bumi Raya. Volume 3 Nomor 1. (Februari 2020).

Surya, YF. (2017). Penerapan Model Pembelajaran Problem Based Learning Untuk Meningkatkan Hasil Belajar Matematika Siswa Kelas IV SDN 016 Langgini Kabupaten Kampar. (Mei 2017) 
Cybernetics: Journal of Research and Educational Studies

Volume 2 Nomor 4, Oktober 2021

Halaman 123-130

Sugiyono. 2017. "Metode Penelitian Pendidikan (Pendekatan Kuantitatif, Kualitatif, $R$ $\mathcal{E} D)^{\prime \prime}$. Bandung : Alfabeta.

Sugiyono, 2019. Metode Penelitian Kuantitatif, Kualitatif dan RED. Bandung: Yogyakarta

Sukmawati,NA. (2017). Pengembangan Lembar Kerja Peserta Didik Berbasis

Problem Based Learning. (Maret 2020)

Utama, WB. (2018). Pengembangan LKPD Berbasis Problem Based Learning Pada Pembelajaran Tematik untuk Meningkatkan Hasil Belajar Siswa Kelas IV SD 